\title{
VPLIV SNP ZNOTRAJ FTO IN LEP GENA NA PRIRAST TELESNE MASE PRI GOVEDU
}

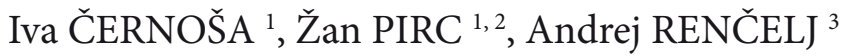

Delo je prispelo 04. julija 2016, sprejeto 19. avguta 2016. Received July 04, 2016; accepted August 19, 2016.

\section{Vpliv SNP znotraj FTO in LEP gena na prirast telesne mase prigovedu}

Prirast telesne mase $\mathrm{v}$ določenem časovnem obdobju je eden pomembnejših parametrov v prireji govejega mesa. Znanih je nekaj kandidatnih genov, ki imajo velik vpliv na lastnosti rastnosti, med njimi zavzemata pomembno mesto lokusa FTO (povezan $z$ maso maščevja in debelostjo) in LEP (leptin). $\mathrm{V}$ poskusu smo ocenili frekvence alelov na dveh lokusih znotraj gena FTO (FTO6 in FTO10) in na enem lokusu znotraj leptinskega gena na vzorcu goveda pasme aberdeen angus (AA) in črno-bele (ČB) pasme. Povezavo teh lokusov s prirasti v 200 dnevnem obdobju (med 165. in 365. dnem starosti) smo preverjali na vzorcu mešane populacije mlečnih in mesnih pasem. Vezave med obema polimorfizmoma znotraj FTO gena nismo mogli potrditi, ker se med eksonom 5 in intronom 5 v FTO genu nahaja mesto $\mathrm{z}$ visoko frekvenco rekombinacij. Na preiskovani populaciji smo dokazali značilen vpliv telesne mase ob rojstvu, pasme in polimorfizmov v FTO genu na prirast. Vpliva polimorfizma $v$ genu LEP nismo mogli potrditi.

Ključne besede: govedo; SNP; prirast telesne mase; leptin; genetika; kandidatni geni; FTO; LEP

\section{UVOD}

$\mathrm{V}$ raziskavah debelosti pri človeku je bilo dokazano, da polimorfizmi v FTO (fat mass and obesity associated, povezan $z$ maso maščevja in debelostjo) genu vplivajo na indeks telesne mase in pojav prekomernega razvoja maščobnega tkiva (Dina in sod., 2007; Frayling in sod., 2007; Loos in Bouchard, 2008; Scuteri in sod., 2007; Wahlen, 2008). FTO je ključen pri uravnavanju

\section{Influence of SNP mutations in FTO and LEP genes on body mass in bovine populations}

Body mass gain in a certain time period is one of the most important parameters in beef production. Some candidate genes, which have major impact on growth traits, are known from the literature, notably among them the FTO (fat mass and obesity-associated) and LEP (leptin) locus. In our experiment, we assessed the frequency of alleles at two polymorphic sites within the FTO gene (FTO6 and FTO10) and at polymorphic site in the LEP gene in a sample of Aberdeen Angus (AA) and Holstein Friesian (HF) breeds. In a larger sample, containing dairy and beef cattle breeds we tested the association of these three SNPs with the body mass gain in a 200-day period (between $165^{\text {th }}$ and $365^{\text {th }}$ day of age). In our material we could not confirm the linkage between two SNPs within the FTO locus, due to the existence of the region with high recombination rate between exon 5 and intron 5 in the FTO gene. We demonstrated significant impact of birth weight, breed and SNPs in the FTO gene on the growth. The effect of the polymorphic site within the LEP gene could not be confirmed.

Key words: cattle; SNP; body mass gain; leptin; genetics; candidate genes; FTO; LEP

homeostaze in vpliva na povišano lipolitično aktivnost $\mathrm{v}$ adipoznem tkivu (Wahlen, 2008; Fredriksson, 2008), kar nakazuje, da je dober kandidat za uravnavanje telesne mase in vnosa hranil. Ker so te lastnosti pomembne tudi pri prireji mesa, so bile v literaturi opisane povezave med polimorfizmi v FTO genu z lastnostmi, kot so razporeditev maščobe $\mathrm{v}$ mišicah, končna telesna masa in povprečen dnevni prirast pri različnih vrstah domačih živali, predvsem pri prašičih (Fontanesi, 2010; Fan.,

1 Univ. v Ljubljani, Biotehniška fak., Jamnikarjeva ulica 101, SI-1000 Ljubljana, Slovenija, e-naslov: iva.cernosa@gmail.com

2 Isti naslov kot 1, e-naslov: zan.pirc@gmail.com

3 Univ. v Ljubljani, Biotehniška fak., Oddelek za zootehniko, Groblje 3, 1230 Domžale, Slovenija, e-naslov: andrej.rencelj@bf.uni-lj.si, andrej.rencelj@gmail.com 
Preglednica 1: Pregled uporabljenih začetnih oligonukleotidov in restrikcijskih encimov Table 1: Primer sequences and restriction enzymes used for PCR-RFLP

\begin{tabular}{|c|c|c|c|c|}
\hline Ime & Začetni oligonukleotid & $\begin{array}{l}\text { Lokacija } \\
\text { na genu }\end{array}$ & $\begin{array}{l}\text { Restrikcijski } \\
\text { encim }\end{array}$ & Literatura \\
\hline FTO6 & $\begin{array}{l}\text { GAGCTGACTCGTTGGGAAAG/ } \\
\text { ACTTTCCGTGTTTTCATGGC }\end{array}$ & Intron 4 & AluI & D. Jevsinek Skok in sod., 2015 \\
\hline FTO10 & $\begin{array}{l}\text { AAGTGGAGAGGTCCAGCAGA/ } \\
\text { TACACGCTATGGTCTGTGGG }\end{array}$ & Intron 5 & AseI/VspI & D. Jevsinek Skok in sod., 2015 \\
\hline LEP & $\begin{array}{l}\text { TGGAGTGGCTTGTTATTTTCTTCT / } \\
\text { GTCCCCGCTTCTGGCTACCTAACT }\end{array}$ & Intron 2 & Bsp143I (Sau3AI) & $\begin{array}{l}\text { Moravčikova in sod., 2012, } \\
\text { Othman in sod., } 2011\end{array}$ \\
\hline
\end{tabular}

2009; Huang in sod., 2011; Szydlowski in sod., 2012) in govedu (Jevsinek Skok in sod., 2016; Rempel in sod., 2012; Zhang in sod., 2011, Wei in sod., 2011). Pri govedu se FTO gen nahaja na 18. kromosomu v bližini QTL regije, ki vpliva na kakovost mesa in vključuje devet eksonov, ki kodirajo 505 aminokislin (Chung, 2014). Naša raziskava je obsegala dva polimorfizma posameznih nukleotidov (SNP) znotraj gena FTO, ki sta bila predhodno povezana $\mathrm{z}$ lastnostmi mesnatosti (Jevsinek Skok in sod., 2015) in polimorfizem posameznega nukleotida (SNP) znotraj gena LEP, ki kodira hormon leptin, enega glavnih regulatorjev aktivnosti adipoznega tkiva. Gen LEP obsega več kot 15.000 baznih parov, tri eksone, ki so ločeni z dvema intronoma, in je pri govedu lociran na 4. kromosomu (Stone in sod., 1996). Vpleten je v uravnavanje vnosa hranil, porabe energije, reproduktivnih funkcij in imunskega odziva (Zhang in sod., 1994), zato je eden izmed pomembnejših lokusov, ki so pri govedu povezani s telesno maso in kakovostjo mesa (Buchanan in sod., 2002; Fitzsimmons in sod., 1998; Lagonigro in sod., 2003). Leptin proizvaja belo adipozno tkivo (Ji in sod., 1998; Zhang, 1994), izražanje leptina pa uravnavajo maščobno tkivo, inzulin, rastni hormon in glukokortikoidi (Houseknecht in Portocarrero, 1998; Leurey in sod., 2003). Polimorfizmi v kodirajočih regijah gena LEP so povezani s količino proizvedenega mleka (Buchanan in sod., 2003; Liefers in sod., 2003), odstotkom telesne maščobe (Buchanan in sod., 2002; Nkrumah, 2004) in vnosom hranil (Liefers in sod., 2002; Oprazadek, 2003). V tej raziskavi smo proučevali vpliv SNP v leptinskem genu na prirast v obdobju med 165. in 365. dnem starosti pri govedu.

Preglednica 2: Frekvence genotipov in izračunane frekvence alelov za lokuse FTO6, FTO10 in LEP s pripadajočo $\chi^{2}$ vrednostjo pri pasmi $A$ A

Table 2: Genotype frequencies and calculated allele frequencies for FTO6, FTO10 and LEP loci with corresponding $\chi 2$ values for Aberdeen angus breed

\begin{tabular}{|c|c|c|c|c|c|c|}
\hline \multicolumn{4}{|l|}{ FTO6 } & \multirow{2}{*}{\multicolumn{2}{|c|}{ Alel }} & \multirow[t]{3}{*}{$x^{2}$} \\
\hline \multirow[t]{2}{*}{$\mathrm{n}=34$} & \multicolumn{3}{|c|}{ Genotip } & & & \\
\hline & GG & GT & TT & G & $\mathrm{T}$ & \\
\hline Število & 14 & 13 & 8 & & & \multirow[t]{2}{*}{2,50} \\
\hline Frekvenca & 0,412 & 0,353 & 0,235 & 0,588 & 0,412 & \\
\hline FTO10 & & & & & & $\chi^{2}$ \\
\hline \multirow[t]{2}{*}{$\mathrm{n}=34$} & \multicolumn{3}{|c|}{ Genotip } & \multicolumn{2}{|l|}{ Alel } & \\
\hline & AA & GA & GG & A & G & \\
\hline Število & 4 & 24 & 6 & & & 5,90 \\
\hline Frekvenca & 0,118 & 0,706 & 0,176 & 0,471 & 0,529 & \\
\hline LEP & & & & & & $\chi^{2}$ \\
\hline \multirow[t]{2}{*}{$\mathrm{n}=34$} & \multicolumn{3}{|c|}{ Genotip } & \multicolumn{2}{|l|}{ Alel } & \\
\hline & AA & $\mathrm{AB}$ & BB & A & B & \\
\hline Število & 2 & 22 & 10 & & & 4,65 \\
\hline Frekvenca & 0,059 & 0,647 & 0,294 & 0,382 & 0,618 & \\
\hline
\end{tabular}


Preglednica 3: Frekvence genotipov in izračunane frekvence alelov za lokuse FTO6, FTO10 in LEP s pripadajočo $\chi^{2}$ vrednostjo pri ČB pasmi

Table 3: Genotype frequencies and calculated allele frequencies for FTO6, FTO10 and LEP loci with corresponding $\chi 2$ values for Holstein Friesian breed

\begin{tabular}{|c|c|c|c|c|c|c|}
\hline \multicolumn{4}{|l|}{ FTO6 } & & & \multirow[t]{3}{*}{$\chi^{2}$} \\
\hline \multirow[t]{2}{*}{$\mathrm{n}=22$} & \multicolumn{3}{|c|}{ Genotip } & \multicolumn{2}{|l|}{ Alel } & \\
\hline & GG & GT & TT & G & $\mathrm{T}$ & \\
\hline Število & 6 & 11 & 5 & & & \multirow[t]{2}{*}{0,000094} \\
\hline Frekvenca & 0,273 & 0,500 & 0,227 & 0,523 & 0,477 & \\
\hline FTO10 & & & & & & $\chi^{2}$ \\
\hline \multirow[t]{2}{*}{$\mathrm{n}=22$} & \multicolumn{3}{|c|}{ Genotip } & \multicolumn{2}{|l|}{ Alel } & \\
\hline & AA & GA & GG & A & G & \\
\hline Število & 15 & 5 & 5 & & & \multirow[t]{2}{*}{2,00} \\
\hline Frekvenca & 0,682 & 0,227 & 0,909 & 0,795 & 0,205 & \\
\hline LEP & & & & & & $\chi^{2}$ \\
\hline \multirow[t]{2}{*}{$\mathrm{n}=22$} & \multicolumn{3}{|c|}{ Genotip } & \multicolumn{2}{|l|}{ Alel } & \multirow{4}{*}{0,36} \\
\hline & AA & $\mathrm{AB}$ & $\mathrm{BB}$ & A & B & \\
\hline Število & 5 & 17 & 0 & & & \\
\hline Frekvenca & 0,227 & 0,773 & 0 & 0,114 & 0,886 & \\
\hline
\end{tabular}

\section{MATERAL IN METODE}

\subsection{PRIPRAVA VZORCEV}

DNA smo izolirali iz vzorcev tkiva goveda (delci ušesa, odvzeti pri označevanju) s proteinazo K po klasičnem postopku (Ghatak, 2013). Na koncu izolacije smo pelete posušili do voskaste konsistence, jim dodali

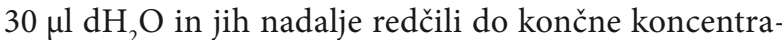
cije $25 \mathrm{ng} / \mathrm{ml}$. Za oceno frekvenc alelov smo uporabili čistopasemske AA in ČB živali, za preverjanje povezav SNP-jev s prirasti pa mešan vzorec živali mlečnih in mesnih pasem.

\subsection{PCR PODVOJEVANJE}

PCR reakcija za FTO6 in FTO10 s končnim volumnom $20 \mu \mathrm{l}$ je vsebovala: $2 \mu \mathrm{l}$ PCR pufra, $2 \mu \mathrm{ldNTP}$ $(2,5 \mathrm{mM}), \quad 0,5 \mu \mathrm{l}$ vsakega začetnega oligonukleotida

Preglednica 4: Pregled števila živali za genotipske kombinacije na lokusih FTO6 in FTO10v vzorcu HF, AA in vzorcu več pasem s pripadajočimi $\chi 2$ vrednostmi za določanje vezave

Table 4: Number of animals for different genotype combinations at loci FTO6 and FTO10 in the samples of HF, AA and in a larger multi breed sample with corresponding $\chi 2$ values for gene linkage

\begin{tabular}{|c|c|c|c|c|}
\hline FTO6 & FTO10 & $\begin{array}{l}\text { Število živali (ČB) } \\
\text { Number of animals (HF) }\end{array}$ & $\begin{array}{l}\text { Število živali (AA) } \\
\text { Number of animals (AA) }\end{array}$ & $\begin{array}{l}\text { Skupno število živali } \\
\text { Number of all animals }\end{array}$ \\
\hline GG & $\mathrm{AA}$ & 2 & 10 & 33 \\
\hline GG & GA & 2 & 1 & 13 \\
\hline GG & GG & 2 & 3 & 23 \\
\hline GT & AA & 9 & 1 & 19 \\
\hline GT & GA & 2 & 10 & 27 \\
\hline GT & GG & 0 & 1 & 4 \\
\hline $\mathrm{TT}$ & AA & 4 & 2 & 12 \\
\hline $\mathrm{TT}$ & GA & 1 & 4 & 9 \\
\hline TT & GG & 0 & 2 & 7 \\
\hline$x^{2}$ & & 4,452488 & 5,061041 & 0,300399 \\
\hline
\end{tabular}


(25 mM), 1,2 $\mu \mathrm{MgCl}_{2}, 0,1 \mu \mathrm{l}$ KAPA Taq DNK polimeraze $(5 \mathrm{U} / \mu \mathrm{l}), 11,7 \mu \mathrm{dH}_{2} 0$ in $2 \mu \mathrm{l}$ izolirane DNK. Postopek podvojevanja je potekal po naslednjem temperaturnem profilu: začetna denaturacija 5 minut pri $94{ }^{\circ} \mathrm{C}, 32$ ciklov 30 sekund pri $94^{\circ} \mathrm{C}, 30$ sekund pri $50^{\circ} \mathrm{C}$ za FTO6 in $53{ }^{\circ} \mathrm{C}$ za FTO10, 35 sekund pri $72{ }^{\circ} \mathrm{C}$ ter zaključno podaljševanje verig 7 minut pri $72{ }^{\circ} \mathrm{C}$.

PCR reakcija za LEP s končnim volumnom $20 \mu \mathrm{l}$ je vsebovala: $2 \mu \mathrm{l}$ PCR pufra, $2 \mu \mathrm{l}$ dNTP $(2,5 \mathrm{mM}), 0,5 \mu \mathrm{l}$ vsakega začetnega oligonukleotida $(25 \mathrm{mM}), 1,2 \mu \mathrm{l}$ $\mathrm{MgCl}_{2}, 0,2 \mu \mathrm{l}$ Taq DNA polimeraze ( $5 \mathrm{U} / \mu \mathrm{l}$, Fermentas),

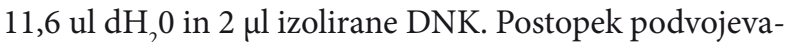
nja je potekal po naslednjem temperaturnem profilu: začetna denaturacija 5 minut pri $95^{\circ} \mathrm{C}, 30$ ciklov 30 sekund pri $95^{\circ} \mathrm{C}, 10$ sekund pri $58^{\circ} \mathrm{C}, 30$ sekund pri $72^{\circ} \mathrm{C}$ ter zaključno podaljševanje verig 7 minut pri $72{ }^{\circ} \mathrm{C}$.

\subsection{RESTRIKCIJA}

$\mathrm{V}$ restrikcijsko reakcijo s končnim volumnom $20 \mu \mathrm{l}$

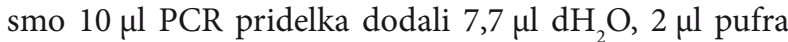
in $0,3 \mu \mathrm{l}$ restrikcijskega encima. Uporabili smo naslednje restrikcijske encime in pufre (vsi proizvajalca THERMO): AluI s pufrom tango za FTO6, AseI s pufrom O za FTO10 in Bsp143I (Sau3AI) s pripadajočim pufrom Bsp143I (Sau3AI) za LEP. Restrikcijske reakcije za vse lokuse smo inkubirali čez noč pri $37^{\circ} \mathrm{C}$.

\subsection{STATISTIČNE METODE}

$\mathrm{Za}$ izračun vpliva genotipa na prirast telesne mase smo izvedli enosmerno in dvosmerno analizo variance (ANOVA) s programom R. Frekvence alelov smo izračunali ročno. Opazovane ter pričakovane frekvence genotipov smo testirali s $\chi 2$ testom, da bi preverili, če so populacije v H-W ravnotežju. Vezavo genov smo preverili s programom EH (Xie in Ott, 1993).

\section{REZULTATI IN RAZPRAVA}

$\mathrm{Za}$ izračun frekvence alelov je bilo pri pasmi AA določenih 34 genotipov za lokuse FTO6, FTO10 in LEP. Rezultati genotipizacije in frekvence alelov so podani v preglednici 1.

Za izračun frekvence alelov za lokuse FTO6, FTO10 in LEP pri ČB pasmi smo imeli na voljo 22 vzorcev.

\subsection{FREKVENCE ALELOV}

Vzorec ČB pasme je bil na vseh proučevanih lokusih v H-W ravnovesju ( $\chi^{2}$ vrednosti manjše od tabelarične vrednosti 3,841) (pregl. 3), medtem ko je bil vzorec goveda pasme AA v H-W ravnovesju le na lokusu FTO6 (pregl. 2), kar je verjetno posledica manjšega števila genotipiziranih osebkov, lahko pa bi to bila tudi posledica selekcije na večjo mesnatost.

\subsection{VEZAVA LOKUSOV}

Zbrani podatki so potrdili našo hipotezo, da lokusa FTO6 in FTO10 nista vezana, kar je pričakovan rezultat, saj so tudi predhodne raziskave pokazale, da se med eksonom 5 in intronom 5 gena FTO nahaja pomembno rekombinacijsko mesto (Jevsinek Skok in sod., 2016; Zhang in sod., 2011). Lokus FTO6 se nahaja v intronu 4, lokus FTO10 pa v intronu 5 in tako oklepata rekombinacijsko mesto. Ker lokusa nista kazala vezave pri nobeni od proučevanih populacij, smo preverili vezavo še $\mathrm{v}$ večjem vzorcu, kjer smo obema čistopasemskim skupinama dodali še skupino različnih mesnih in kombiniranih pasem ter na skupnem vzorcu potrdili, da vezave med lokusoma FTO6 in FTO10 ni moč zaznati.

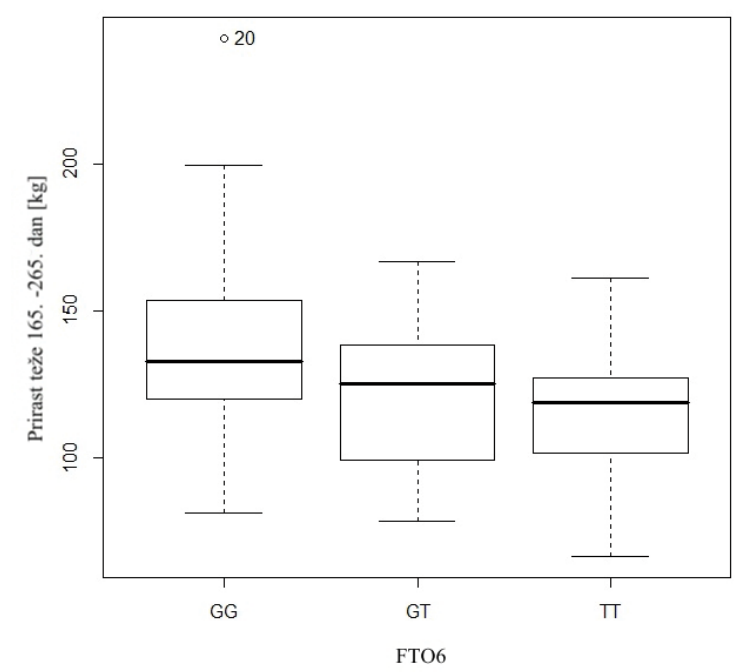

Slika 1: Prirast telesne mase med 165. in 365. dnem glede na genotip na lokusu FTO6

Figure 1: Body mass gain between $165^{\text {th }}$ and $365^{\text {th }}$ day of age regarding the genotype at FTO6 locus 


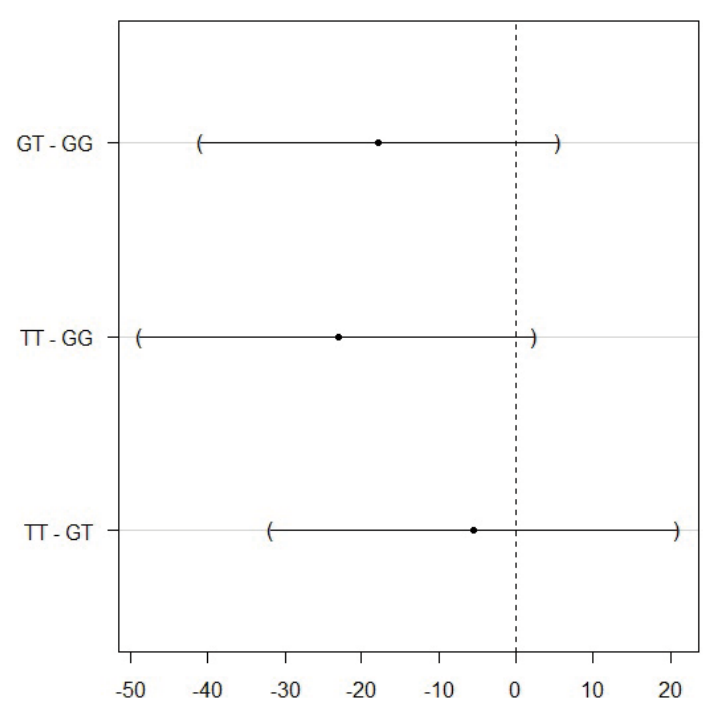

Slika 2: Intervali zaupanja za FTO6

Figure 2: Confidence intervals for FTO6 locus

\subsection{VPLIV GENOTIPA NA PRIRAST TELESNE MASE}

Z enosmerno ANOVO smo pokazali, da obstaja statistično mejno značilna razlika med živalmi različnih pasem $(\mathrm{n}=53) \mathrm{z}$ različnimi genotipi na SNP FTO6 $(p=0,0628)$. Primerjava povprečij po parih je pokazala, da so živali z genotipom GG $(138,9 \mathrm{~kg} \pm 35,9 \mathrm{~kg})$ v 200 dneh, od 165. do 365. dneva starosti priraščale nekoli-

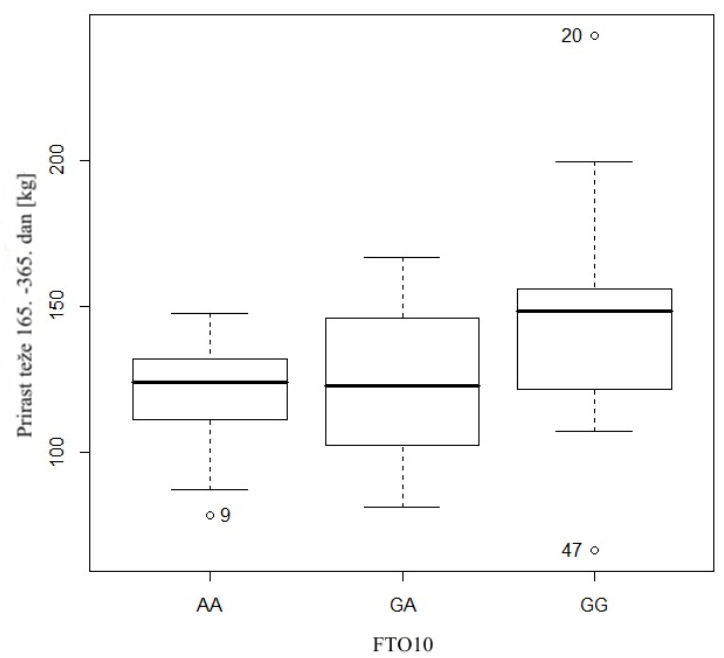

Slika 3: Prirast telesne mase med 165. in 365. dnem glede na genotip na lokusu FTO10

Figure 3: Body mass gain between 156th and 365th day of age regarding the FTO10 locus

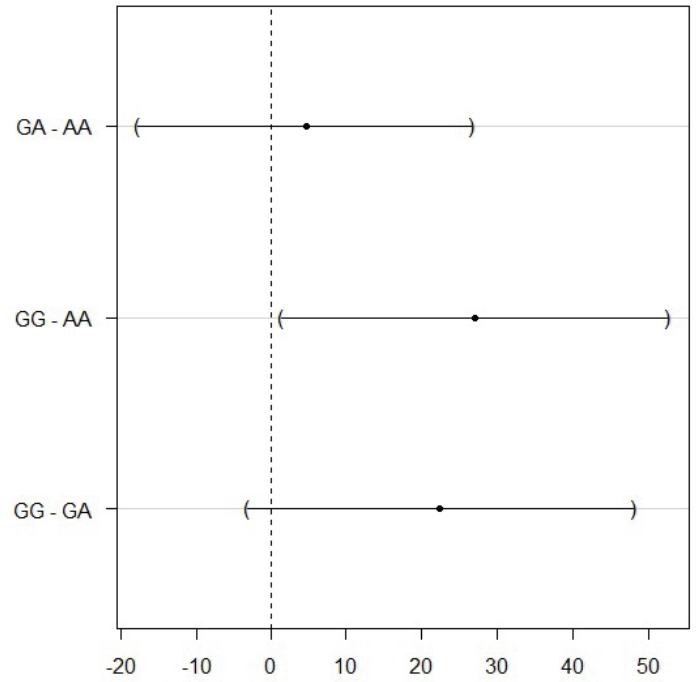

Slika 4: Intervali zaupanja za FTO10

Figure 4: Confidence intervals for FTO10 locus

ko več kot tiste $\mathrm{z}$ genotipom TT $(115,7 \mathrm{~kg} \pm 23,4 \mathrm{~kg}$, $p=0,0813)$ (slika 1 in 2).

Z enosmerno ANOVO smo lahko pokazali statistično značilno razliko na skupnem vzorcu živali neločljivih pasem $(\mathrm{n}=53) \mathrm{z}$ različnimi genotipi na SNP FTO10 $(p=0,0463)$. Primerjava povprečji po parih je pokazala, da so bikci z genotipom GG $(146,4 \mathrm{~kg} \pm 44,6 \mathrm{~kg})$ v 200 dneh, od 165. do 365. dneva prirasli značilno več kot tisti $\mathrm{z}$ genotipom AA $(119,4 \mathrm{~kg} \pm 18,1 \mathrm{~kg}, p=0,0366)$ in ma-

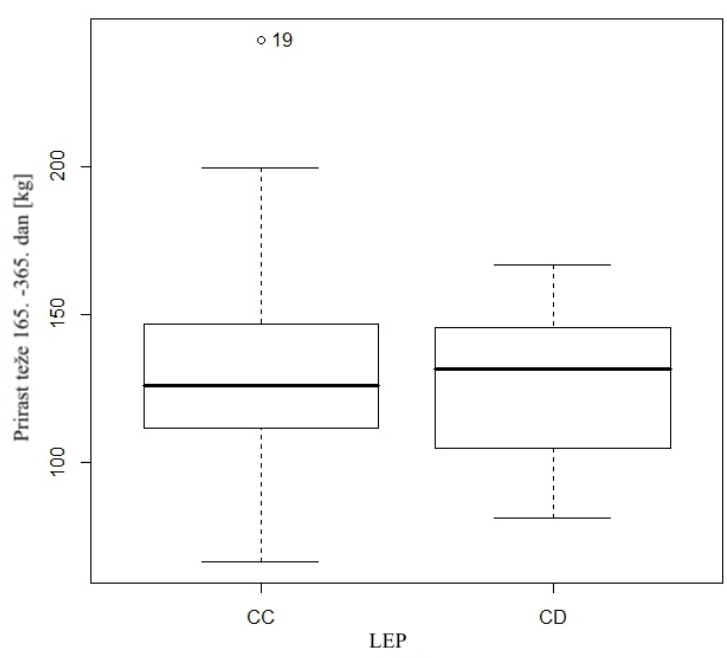

Slika 5: Prirast telesne mase med 165. in 365. dnem glede na genotip na lokusu LEP

Figure 5: Body mass gain between 156th and 365th day of age regarding the LEP locus 


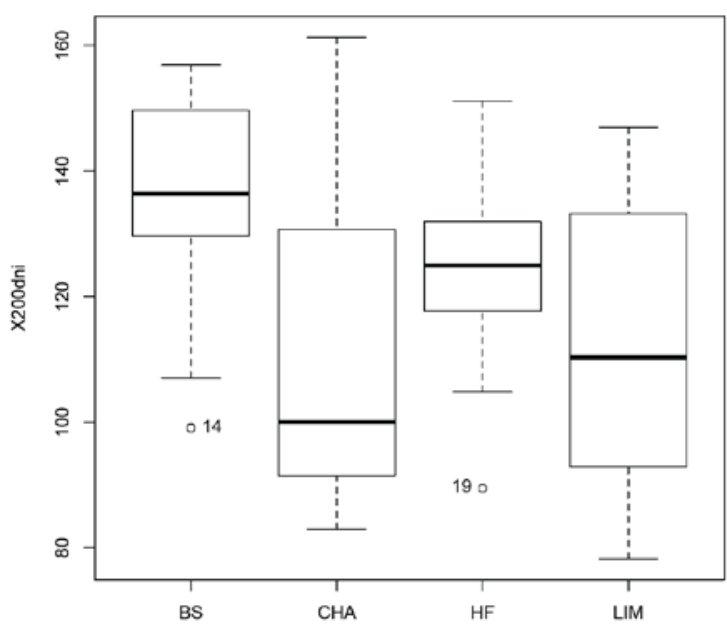

Slika 6: Prirast telesne mase med 165. in 365. dnem glede na pasmo (BS: rjava; CHA: šarole; HF: črno-bela; LIM: limuzin)

Figure 6: Body mass gain between 156th and 365th day of age regarding the breed (BS: Brown cattle; CHA: charolais; HF: Holstein Frisian; LIM: Limousin)

lenkostno več od tistih z genotipom GA $(123,9 \mathrm{~kg} \pm 26,3$, $p=0,0965)$ (slika 3 in 4).

Z enosmerno ANOVO smo pokazali tudi, da podatki niso statistično značilni $(p=0,633)$ za vpliv genotipa na lokusu LEP za priraste v 200 dnevnem obdobju od 165. do 365. dneva starosti (slika 5).

V dvosmerni analizi ANOVA smo poleg genotipov upoštevali tudi pasemsko pripadnost živali in telesno maso živali ob rojstvu ter ugotovili, da ima največji statistično značilen vpliv telesna masa ob rojstvu $(p<0,01)$, nato pasma $(p<0,05)$ in SNP označevalca na lokusih FTO6 $(p<0,05)$ in FTO10 $(p<0,05)$. Podobno kot v enosmerni ANOVA analizi učinek genotipa na lokusu LEP ni bil statistično značilen. Vpliv pasme na prirast telesne mase v obdobju med 165. in 365. dnevom je prikazano na sliki 6.

\section{ZAHVALE}

Za pomoč pri izračunih in interpretaciji se zahvaljujeva doc. dr. Nataši Štajner in prof. dr. Katarini Košmelj.

\section{$5 \quad$ VIRI}

Buchanan, F. C., Fitzsimmons, C. J., Van Kessel, A. G., Thue, T. D., Winkelman-Sim, C., \& Schmutz, S. M. (2002). Association of a missense mutation in the bovine leptin gene with carcass fat content and leptin mRNA levels. Genetics Selection Evolution, 34, 105-116. doi:10.1186/1297-9686-34-1-105
Buchanan, F. C., Van Kessel, A. G., Waldner, C., Christensen, D. A., Laarveld, B., \& Schmutz, J. S. N. (2003). Hot topic: an association between a leptin single nucleotide polymorphism and milk and protein yield. Journal of Dairy Science, 86, 3164-3166. doi:10.3168/jds.S0022-0302(03)73918-6

Chung. (2014). Novel SNP in the coding region of the FTO gene is associated with marbling score in Hanwoo (Korean cattle). Journal of Animal Science and Technology, 56, 27. doi:10.1186/2055-0391-56-27

Dina, C., Meyre, D., Gallina, S., Durand, E., Korner, A., Jacobson, P., ... Froguel F. (2007). Variation in FTO contributes to childhood obesity and severe adult obesity. Nature Genetics, 39, 724-726. doi:10.1038/ng2048

Fan, B., Du, Z. Q., \& Rothschild, M. F. (2009). The fat mass and obesity associated (FTO) gene is associated with intramuscular fat content and growth rate in the pig. Animal Biotechnology, 20, 58-70. doi:10.1080/10495390902800792

Fontanesi, L., Scotti, E., Buttazzoni, L., Dall'Olio, S., Bagnato, A., Fiego, D. P. L., ... Russo, V. (2010). Confirmed association between a single nucleotide polymorphism in the FTO gene and obesity-related traits in heavy pigs. Molecular Biology Reports, 37, 461-466. doi:10.1007/s11033-009-9638-8

Fitzsimmons, C. J., Schmutz, S. M., Bergen, R. D., \& McKinnon, J. J. (1998). A potential association between the BM 1500 microsatellite and fat deposition in beef cattle. Mammalian Genome, 9, 432-434. doi:10.1007/s003359900791

Frayling, T. M., Timpson, N. J., Weedon, M. N., Zeggini, E., Freathy, R. M., Lindgren, C. M., ... McCarthy M. I. (2007). A common variant in the FTO gene is associated with body mass index and predisposes to childhood and adult obesity. Science, 316(5826), 889-894. doi:10.1126/science.1141634

Fredriksson, R., Hagglund, M., Olszewski, P. K., Stephansson, O., Jacobsson, J. A., Olszewska, A. M., ... Schiöth H. B. (2008). The obesity gene, FTO, is of ancient origin, up-regulated during food deprivation and expressed in neurons of feeding-related nuclei of the brain. Endocrinology, 149(5), 2062-2071. doi:10.1210/en.2007-1457

Ghatak, S., Muthukumaran, R. B., \& Nachimuthu, S. K. (2013). A Simple Method of Genomic DNA Extraction from $\mathrm{Hu}-$ man Samples for PCR-RFLP Analysis. Journal of Biomolecular Techniques, 24(4), 224-231. doi:10.7171/jbt.132404-001

Houseknecht, K. L., \& Portocarrero, C. P. (1998). Leptin and its receptors: regulators of whole-body energy homeostasis. Domestic Animal Endocrinology, 15(6), 457-475. doi:10.1016/S0739-7240(98)00035-6

Huang, J., Yang, Y., Liu, G., Zhang, J., Dong, X., Bai, Y., \& Fang, M. (2011). Molecular cloning and characterization of the porcine FTO promoter and coding regions. Molecular Biology Reports, 38(4), 2855-62. doi:10.1007/s11033-010-0431-5

Jevsinek Skok, D., Kunej, T., Kovač, M., Malovrh, S., Potočnik, K., Petrič, N., ... Horvat, S. (2016). FTO gene variants are associated with growth and carcass traits in cattle. Animal Genetics, 47(2), 219-222. doi:10.1111/age.12403 doi:10.1111/age.12403

Ji, S., Willis, G. M., Scott, R. R., \& Spurlock, M. E. (1998). Partial cloning and expression of the bovine leptin gene. Animal Biotechnology, 9(1), 1-4. doi:10.1080/10495399809525887

Lagonigro, R., Wiener, P., Pilla, F., Woolliams, J. A., \& Williams, J. L. (2003). A new mutation in the coding region of the bo- 
vine leptin gene associated with feed intake. Animal Genetics, 34(5), 371-374. doi:10.1046/j.1365-2052.2003.01028.x

Leury, B. J., Baumgard, L. H., Block, S. S., Segoale, N., Ehrhardt, R. A., Rhoads, R. P., ... Boisclair, Y. R. (2003). Effect of insulin and growth hormone on plasma leptin in periparturient dairy cows. American Journal of Physiology - Regulatory, Integrative and Comparative Physiology, 285(5), 1107-1115. doi:10.1152/ajpregu.00320.2003

Liefers, S. C., te-Pas, M. F. W., Veerkamp, R. F., \& van der Lende, J. T. (2002). Associations between leptin gene polymorphisms and production, live weight, energy balance, feed intake, and fertility in Holstein heifers. Journal of Dairy Science, 85(6), 1633-1638. doi:10.3168/jds.S00220302(02)74235-5

Liefers, S. C., Veerkamp, R. F., te-Pas, M. F. W., Delavaud, C., Chilliard, Y., \& van der Lende, J. T. (2003). Leptin concentrations in relation to energy balance, milk yield, intake, live weight, and estrus in dairy cows. Journal of Dairy Science, 86(3), 799-807. doi:10.3168/jds.S0022-0302(03)73662-5

Loos, R. J., \& Bouchard, C. (2008). FTO: the first gene contributing to common forms of human obesity. Obesity Reviews, 9(3), 246-50 doi:10.1111/j.1467-789X.2008.00481.x

Moravčíková, N., Trakovická, A., \& Kasarda, R. (2012). Polymorphism within the Intron Region of the Bovine Leptin Gene in Slovak Pinzgau Cattle. Animal Science and Biotechnologies, 45(1), 211-214.

Nkrumah, J. D., Li, C., Basarab, J. B., Guercio, S., Meng, Y., Murdoch, B., ... Moore, S. S. (2004). Association of a single nucleotide polymorphism in the bovine leptin gene with feed intake, feed efficiency, growth, feeding behaviour, carcass quality and body composition. Canadian Journal of Animal Science, 84(2), 211-219. doi:10.4141/A03-033

Oprzadek, J., Flisikowski, K., Zwierzchowski, L., \& Dymnicki, E. (2003). TG-repeat lenght polymorphism in the 5 '-noncoding region of the growth hormone receptor gene in cattle and its association with meat production traits. Animal Science Papers and Reports, 21, 135-145.

Othman, E. Othman, Fawzia, A. Zayed, Ali A. El Gawead, \& Medhat, R. A. El-Rahman. (2011). Genetic polymorphism of two genes associated with carcass trait in Egyptian buffaloes. Journal of Genetic Engineering and Biotechnology, 9(1), 15-20. doi:10.1016/j.jgeb.2011.05.003
Rempel, L. A., Casas, E., Shackelford, S. D., \& Wheeler, T. L. (2012). Relationship of polymorphisms within metabolic genes and carcass traits in crossbred beef cattle. Journal of Animal Science, 90(4), 1311-6. doi:10.2527/jas.2011-4302

Scuteri, A., Sanna, S., Chen, W. M., Uda, M., Albai, G., Strait, ... Abecasis G. R. (2007). Genome-wide association scan shows genetic variant in the FTO gene are associated with obesity-related traits. PLoS Genetics, 3(7), 115. doi:10.1371/journal.pgen.0030115

Stone, R. T., Kappes, S. M., \& Beattie, C. W. (1996). The bovine homolog of the obese gene maps to Chromosome 4. Mammalian Genome, 7(5), 399-400. doi:10.1007/s003359900119

Szydlowski, M., Salamon, S., Grzes, M., \& Switonski, M. (2012). SNP in the $5^{\prime}$ flanking region of the pig FTO gene is associated with fatness in Polish Landrace. Livestock Science, 150(1-3), 397-400. doi:10.1016/j.livsci.2012.09.001

Zhang, B., Zhang, Y., Zhang, L., Wang, J., Li, Z., \& Chen, H. (2011). Allelic polymorphism detected in the bovine FTO gene. Molecular Biotechnology, 49(3), 257-262. doi:10.1007/s12033-011-9400-Z

Zhang, H. M., DeNise, S. K., \& Ax, R. L. (1994). Rapid communication: diallelic single-stranded conformational polymorphism detected in the bovine prolactin gene. Journal of Animal Science, 72, 256

Zhang, Y., Proenca, R., Maffey, M., Barone, M., Leoppld, L., \& Friedman, J. M. (1994). Positional cloning of the mouse obese gene and its human homologue. Nature, 372(6505), 425-432. doi:10.1038/372425a0

Wahlen, K., Sjolin, E., \& Hoffstedt, J. (2008). The common rs 9939609 gene variant of the fat mass- and obesity-associated gene FTO is related to fat cell lipolysis. The Journal of Lipid Research, 49(3), 607-611. doi:10.1194/jlr.M700448-JLR200

Wei, S., Zan, L., Ujan, J. A., Wang, H., Yang, Y., \& Adoligbe, C. (2011). Novel polymorphism of the bovine fat mass and obesity-associated (FTO) gene are related to backfat thickness and longissimus muscle area in five Chinese native cattle breeds. African Journal of Biotechnology, 10(15), 2820-2824. doi:10.5897/AJB10.2192

Xie, X., \& Ott, J. (1993). Testing linkage disequilibrium between a disease gene and marker loci. The American Journal of Human Genetics, 53, 1107. 